\title{
STRATEGIC AND DIGITAL MARKETING IN CULTURAL INSTITUTIONS AND THE IMPACT OF THE COVID-19 PANDEMIC - A COMPARATIVE ANALYSIS OF TWO CASE STUDIES
}

\author{
Aleksandra Krajnović1, *, Ivona Vrdoljak Raguž² and Antonija Perković ${ }^{3}$
}

\author{
${ }^{1}$ University of Zadar, Department of Economics \\ Zadar, Croatia \\ ${ }^{2}$ University of Dubrovnik, Department of Economics and Business Economics \\ Dubrovnik, Croatia \\ ${ }^{3}$ Croatian National Theater in Zadar \\ Zadar, Croatia
}

DOI: $10.7906 /$ indecs.19.2.6

Received: 29 January 2021.

Regular article

Accepted: 6 June 2021.

\begin{abstract}
This article investigates the impact of the coronavirus pandemic COVID-19 on marketing within cultural institutions, specifically in the field of digital marketing. The aim is to examine how the pandemic has affected digital strategies, marketing communication, and the performance itself - the presentation of cultural programs. The primary research was conducted in Croatia, using the method of semi-structured in-depth interviews with managers in two cultural institutions in Zadar and Dubrovnik at the end of 2020. A qualitative descriptive analysis was performed to answer the question of how cultural institutions have adapted to the crisis, especially when it comes to the marketing and the performance of cultural programs. The results show a certain degree of flexibility in adapting to the new conditions, in a way that marketing communication after the crisis turned more strongly towards digital media and was followed by adjustments to the cultural programs and their performance, as well as the budget for cultural activities. The marketing digital communication played a key role in this, which proves that cultural management in the era of the pandemic adopted the socalled digital-first paradigm, modeled on the for-profit companies. The authors conclude that culture, as a social need and necessity, will continue its activity after the crisis caused by the COVID-19 pandemic, but that it will also function in new and creative ways.
\end{abstract}

\section{KEY WORDS}

COVID-19, coronavirus, digital marketing, non-profit marketing, cultural institutions

\section{CLASSIFICATION}

JEL: M15, M31, Z11 


\section{INTRODUCTION}

The current pandemic Covid-19 has had an enormous effect on global society [1]. In doing so, some social activities and sectors are particularly vulnerable, such as sports, tourism, cultural activities, and the event industry in a broader sense. Within a month of its detection, WHO flagged the COVID-19 outbreak as Public Health Emergency of International Concern on $30^{\text {th }}$ January 2020 [2], and on $11^{\text {th }}$ February 2020 the disease and the virus causing the disease was officially named COVID-19 and SARS-CoV2 respectively. By $11^{\text {th }}$ March 2020, the world witnessed the COVID-19 outbreaks in 114 countries, and given its outreach, WHO characterized COVID-19 as a pandemic [3]. The COVID-19 pandemic has become a significant global crisis that is profoundly affecting almost all aspects of economic and social life globally. Governments have closed borders, banned mass gatherings, and enforced social distancing, generating a 'new normal' for businesses and individual citizens. This global crisis has caused the biggest depression of the 1930s [4] and it requires individuals, organizations, and nations to take necessary steps to cope, as pointed out by numerous authors. For example, Lindström proposes to develop a comprehensive and systematic understanding of the impact of the COVID-19 pandemic on individuals' career development and possible coping strategies [5]. In this article, the authors discuss the impact of the COVID-19 pandemic on cultural institutions, and, more broadly, on the event industry. The topic is current and insufficiently researched. Madray states that the event industry, worth $\$ 1000$ billion, is one of the "most affected industries of this pandemic globally", and adds that "until April 2020 the maximum loss in the event industry is about more than $\$ 666$ million, due to cancellation of events worldwide" and has "85,9 million jobs at stake" [6, p.533]. The research that analyzes the issue of pandemics in the social context focuses on the following: the impact of the pandemic on economic, social and political relations [7,8], on the global economy $[9,10]$, or economies of individual countries or world economic macro-regions for example, the USA [11], Asia [12] and Great Britain [13]. It is interesting to note that these studies also analyze the experiences of historical pandemics, especially the Spanish flu in 1918, and even the potential pandemic H5N1 (avian flu), which began in late 2003, the outbreak of SARS1 in 2003, as well as the reappearance of the disease in 2005, so it can be said that the mentioned authors Bloom et al. in their 2005 paper, almost prophetically predicted the current global pandemic. Smith et al., in their 2009 paper, cite Macfarlane \& Lim, and state that in the 20th century there were three major influenza pandemics - the one in 1918, 1957, and 1968-1969 [13].

Currently, the effects of COVID-19 on the business of cultural institutions remain unexplored. The coronavirus disease (SARS-CoV-2) and the COVID-19 pandemic originated in China in late 2019 and spread throughout the world through international travel causing immediate and immeasurable consequences. The coronavirus and the COVID-19 pandemic have caused a unique crisis in entire human history because they affected the whole world, which has never happened before. Until this event, it was considered that only terrorism, confrontations of great powers, and/or financial crises, such as the one that occurred in 2008, could cause major global disturbances which, in turn, could lead to widespread tectonic consequences [14, p.31]. For now, Croatia has managed to ensure that these events do not overwhelm us, that we do not have a large number of infected and deceased, that there are no significant disturbances in the functioning of the State and everyday life, and that the crisis does not cause domino effects that would create additional significant damage [14, p.49]. The far-reaching consequences of the pandemic on society and the economy, as noted earlier, are still being investigated. Many authors investigate the impact of the pandemic on tourism [15-17] and on sport $[18,19]$, i.e. sporting events [20]. When it comes to the event industry, and within the context of the topic explored in this article, the research is focused mainly on two 
segments. One segment researches the effects of digitalization in the event industry [21], while the other is focused on crisis management [22], and risk management in the aforementioned industry [23, 24]. Mohanty et al. state that, by being the biggest pandemic of the $21^{\text {st }}$ century, the COVID-19 outbreak has had catastrophic impacts on almost all spheres of economic activity, and that the global events, as one of the crucial wings of tourism, have precisely been among the hardest-hit sectors [25]. The same authors add: "The massiveness of the events in terms of volume, size, and scope makes them a potentially easy target for not just COVID-19, but also any infectious disease outbreaks. Events suffer from the innate disadvantage of higher vulnerability to internal or external disturbances meaning any small disturbance in the internal and external environment causes catastrophic impacts on any event no matter how neatly the action plan for the event is designed" [25, p.3].

In this article, the authors are focused on non-profit marketing, specifically marketing in cultural institutions, in the context of the coronavirus pandemic COVID-19. The purpose of the research is to examine how the pandemic caused changes in programs, budgeting, marketing strategy, performance, and marketing channels of communication with users of cultural programs. A comparative analysis of two case studies in the Republic of Croatia was performed - the renowned Dubrovnik Summer Festival in Dubrovnik and the Croatian National Theater in Zadar. The purpose of the article was to examine the extent to which the COVID-19 pandemic caused changes in the marketing strategy and the very performance of the cultural institution's programs. The primary research was conducted using the method of in-depth semi-structured interviews, where, towards the end of 2020, the managers/program managers in the mentioned institutions were interviewed, followed by a comparative qualitative analysis. The limitation of the research refers to the fact that only two case studies have been analyzed in the article. Future researches, therefore, would require an expanded focus directed towards other institutions in the country and abroad.

The expected scientific contribution of this article is premised on the expanding of existing research about the impact of the COVID-19 pandemic on cultural activities. It has already been noted that both previous and current research has focused on the effects of the pandemic on society and the economy, as well as on sports, tourism, and the event industries. However, the research gap is particularly evident when it comes to the impact of a pandemic on cultural activities, such as theater and classical music concerts. The existing research in this area only analyzes the impact of the pandemic on festivals, as one of the "products" in the event industry. Thus, for example, Davis explores the future of festivals in the post-COVID period [26], while Salti questions whether the pandemic will lead to a new paradigm relating to film festivals [27]. Regarding the festivals during a pandemic, Surplice emphasizes the safety risks and the importance of health and safety regulations and crisis management in event management [28], where Surplice quotes Szatan and states that "many festivals are not insured against pandemics; therefore, many have been forced to cancel or postpone throughout the pandemic. "[28, p.2]. Szatan, in a quoted article in The Guardian from April 2020, also writes the following: "The 2020 festival season is over - or is it? Some events are trying to postpone until autumn, but the odds are not looking good." [29]. Mohatny et al., in the aforementioned study, state by citing Ishol \& Phin, that events are considered as one of the biggest sources for the transmission of infectious disease. Therefore, cancellation or postponement of the events, at least when it comes to large events, is always considered as the preferred decision when it comes to a pandemic situation. Events and festivals, conducted without any proper regulation can become "super spreading" events. In their 2020 study, the same authors further state that the outbreak of COVID-19 has knocked down the event industry around the world. Amidst the COVID-19 crisis, immediate restrictions were imposed by the government on travel activities and event gatherings. This resulted in 
irreparable loss to the tourism sector events. Most events were cancelled and postponed by the organizers as per the guidelines announced by the government-exhibitions, concerts, conferences, sports events, marriages, and trade shows, etc. The same authors also state that to mitigate the chance of shut down or collapse, the event industry may lay off employees or deduct salaries [25]. Davis questions the impact and future of the pandemic on festivals and other events and states the following: What are the long-term impacts for the future of the industry, and accessibility to these events? Will greater restrictions be placed on licensing, with a maximum number of attendees allowed? Will there be a certification scheme for attendees and participants based on current testing methods for COVID-19? Will festivals become more "exclusive", or will there be more smaller-scale accessible organizations that work within a new "sharing economy"? Such thoughts are joined by the authors of this article where they also question some of the issues and possibilities for the future of the festival industry, as well as whether it is a potential shift occurring in economic paradigms as an outcome of the pandemic [26]. In such conditions, it is interesting to note that scientists and practitioners in the event industry have noticed two basic possibilities: to cancel or postpone the festival, or to offer a so-called hybrid event, that will be adapted to the pandemic conditions. In this sense, Mat Schulz, the artistic director of Kraków's Unsound, in April 2020, said the experimental arts festival is still set to run in October (2020) but will take a hybrid form: "We can not simply plow ahead as per usual", Schulz says. "We're trying to consider what form Unsound could take in practical terms, as well as consider how we can respond to the current crisis conceptually" [29]. Schulz also questions the future of music festivals in the post-COVID period and states: "There's going to be a huge craving for live music after this. The experience of collectively listening or dancing together - how that need is met will change in ways we can not yet predict". The research of the authors in this article relies on the abovementioned theses, while they also question in what form the event industry, i.e. cultural activity, has adapted to the current conditions of the pandemic, on the example of two institutions in Croatia, which also represents the main contribution of this research. A similar study was performed by the previously cited authors Madray et al. [6] by surveying experts in the event industry. A special contribution of the proposed paper lies in the analysis of the impact of digitalization in business on the crisis management in cultural institutions caused by the pandemic, especially in the field of marketing communication.

The article is structured as follows. The first part of the article presents a brief overview of literature about marketing orientation and digital marketing in cultural institutions before the COVID-19 pandemic, followed by a synthesis of available research on the impact of the current pandemic on cultural institutions and digital marketing communication. The third segment describes the selected methodology and the comparison with similar research, followed by a presentation of the research results and a comparative analysis. The concluding part of the article states the concluding remarks and discussion.

\section{MARKETING ORIENTATION AND DIGITAL MARKETING IN PUBLIC CULTURAL INSTITUTIONS BEFORE THE COVID-19 PANDEMIC}

Marketing orientation was initially exclusively focused on business entities and concentrated on meeting the needs and desires of customers in the business sector. Over the last decades, there has been a change in the understanding of the function and role of marketing orientation, which extends from business to both civil society and the public sector, with an emphasis on cultural institutions. By adopting marketing orientation, cultural institutions have radically changed their business philosophy. The earlier business philosophy focused on objects or exhibits was re-oriented towards visitors of cultural institutions [30]. 
The marketing orientation in culture focuses on understanding the needs and wants of different cultural content final recipients. According to Hill et al. "marketing is an integrated management process which provides mutually satisfying exchange relationships with customers on the route to achieving organizational and artistic objectives" [31]. Instead of orientation to objects or products, the implementation of cultural marketing achieves harmony between customer preferences and cultural institutions. Marketing orientation plays a key role in the demystification of the contents of cultural institutions; therefore, marketing should be considered as a tool by which a potential demand for contents of cultural institutions is translated into real demand.

Marketing managers in cultural fields should investigate deeply the target cultural consumers' understanding, preferences, and perceptions. It is understandable because marketing strategies can indeed determine appropriate strategies in cultural fields to offer the best services in the most beneficial way for both parts of businesses [32]. Colbert \& St James studied three central themes in arts marketing research: an emerging challenge to the traditional "supply-side marketing" assumption underlying arts marketing; the role of consumers as co-creators of artistic experiences; and unique aspects of arts marketing management - that is, branding of artistic products, pricing of artistic products, cultivating customer loyalty, and incorporating unique funding sources such as fundraising and sponsorships [33].

Camarero et al. explored whether museums' external relationships depend on managers and internal relationships as well as on the mode of governance. They concluded that close relationships with the external environment require managerial social capital and supportive culture that favours internal cohesion. Finally, public museums directly run by government entities remain too bureaucratic and lack incentives to promote internal cohesion as well as relationships with customers and other stakeholders. Public cultural institutions turn to build strong partnerships at the community level in which they operate in the spirit of democracy and the culture of dialogue. In this way, cultural institutions strongly contribute to the development of the cultural identity of cities and activity that is in line with the principles of developing a brand of a city or a tourist destination [34].

To raise the overall level of user experience, numerous cultural institutions systematically and continuously invest in the development of interactive content through which visitors are exposed to cultural contents by personal and customized experiences of an active participant. This orientation reflects the trend in the cultural market that can be described by the phrase "culture is not only creative, but it also instigates creation" [35, p.31]. Already in the first phases of marketing development in cultural institutions, the focus of the research was on conceptualizing the experiences of visitors to cultural institutions. As the offer of cultural content become more and more diverse, the marketing of cultural institutions is focused on the question of how to offer visitors additional value for money, how to stand out in the minds of the target group of customers and gain their loyalty. The answer to these questions lies in the need to provide extraordinary, unique, and exclusive experiences that will engulf visitors for their uniqueness and exceptional emotional, multisensory and aesthetic nature [36]. The author also points out that the level of experience of visitors to a cultural event is influenced by the interaction between the overall quality of services, the perceived value for the time and money invested, and the satisfaction of visitors with the overall marketing relationships at the cultural institution level. In his research Lehman seeks to answer the questions: What do museums see as the drivers of change in the museum sector in recent years? How do they think the public has changed? How have museums responded to the changes in both society and their visitors? [37]. 
The development of information and communication technology is applicable in almost all fields of human activities, as well as in the marketing of public cultural institutions. Digital media represent with their interactivity, multimedia, and real-time user communication capability a very important tool of marketing communication for contemporary cultural institutions, especially concerning attracting new visitors and building loyalty relationships with existing visitors to a cultural institution. Although Digital Transformation initiatives vary from the use of digital technologies for improvement of one process, product or service to the change of the entire work logic and the way how organizations create value for their customers, they present the inevitable path for surviving onto today's market. Mazzone identifies this shift as "Digital or Death", while Kreutzer defines the term "Digital Darwinism", as an evolutional question of survival or extinction depending on company's ability to adapt itself to new digital environment [38, p.126].

Digital marketing can be defined as a process aimed at identifying and satisfying the desires and needs of potential target customers with information and communication technology, with an emphasis on the Internet. Considering that we live in a digital-centric world where "consumer consumerism is on autopilot", the Internet has changed the classic ways of running a business [39]. Technological advances have led to the creation of completely new and different patterns of marketing communication between providers of goods and services, including cultural institutions, and end-users. The term 'digital marketing' has evolved from a term that describes the marketing of products and services using digital channels, to an umbrella term that describes the process of using digital technologies to acquire and build consumer preferences, promote brands, retain consumers and increase sales. Digital marketing can also be defined as an adaptable, technology-enabled process by which companies work with consumers and partners to collaboratively create, communicate, deliver and maintain value for all stakeholders" [40].

Compared to traditional marketing, digital marketing has enabled interactivity and interconnectivity with end-users of products and services. Email, SMS messaging, and social networking services such as Facebook, Myspace, or LinkedIn allow connecting people of similar attitudes and interests around the world, regardless of their geographical location or time zone. Online social communities are created through interactivity and interconnectivity, and they share common attitudes, values, and affinities. According to Wells the term "social networking" cannot be revised without alongside the term "social media". Social networks are considered as platforms which focuses on the relationship between people who share mutual interests, connections and activities, while social media are determined as means of communication, which provides people to reach and influence others [41, pp.102-103]. These digital marketing features greatly facilitate the process of gaining insight into attitudes of particular social groups and the process of segmentation, targeting, and market positioning as well as the development of targeted marketing communication, which is an important feature of digital media over conventional mass media such as radio or television [42]. The frequency of marketing communication and communication, in general, is significantly increasing as information and communication technology speeds up and facilitates the process of creating, publishing, accessing, and consuming digital content. For this reason, the level of consumer awareness of different products, services, or programs has increased significantly in a relatively short time since the disclosure of information. According to Ryan \& Jones, this creates the basis for eliminating information asymmetry and developing relationship marketing [43].

Digital (r)evolution has led to a significant increase in the amount of information available to a single user and searching for all available information can cause a lack of concentration and the loss of focus, as well as the inability to delve deeper into meaningful information to reach conclusions. To help the Internet users better navigate the available "abundance of information", they have several filters at their disposal that narrow the search for results 
according to the user's interests and preferences. Personalized search features help eliminate unnecessary and irrelevant content for the user. Precisely because of the selectivity of information that the target user accesses, the task of digital marketing staff is to make the content attractive and interesting, enough to capture the attention and interest of target users [44].

In traditional marketing communication, the provider of products and services is the primary initiator of communication, and potential consumers are passive recipients of the message. In the digital marketing era, communication patterns are changing, and potential consumers can look back at the sender's communication message, send reviews, or share content with users with whom they are connected in the digital community. The democracy of digital media is reflected in public debates, forums, polls, user-posted content, and opinion polls [45]. All the above features of the Internet as a medium significantly enhance the bargaining power of users in the market.

The digital marketing era leads to a significant change in the development of relationships between marketers and potential users of their services. Social media has become omnipresent. Statista predicted in 2018 that within three years, a third of Earth's entire population will actively use it [41, p.102]. Due to a high level of information and involvement of users in social networks and their significant bargaining power, customers are actively involved in the process of making decisions about the features of products and services. Through collaborative customer relationships, satisfying the needs, desires, and preferences of potential and actual customers is approached in a new and direct way. Customers who actively participate in the process of creating products and services and whose suggestions are respected by the producer (provider) are called prosumers (PROviders/ConSUMERS) [43].

\section{CULTURE AND CULTURE MARKETING IN THE AGE OF THE COVID-19 PANDEMIC}

In the current era of the pandemic, there is the impression that culture and cultural content are often left aside, and that there are "more important" human activities that are given more attention in this time of crisis on a global scale. But participating in cultural events is an important determinant of an individual's quality of life [46, p.74]. In 1948 The Universal Declaration of Human Rights recognized that "everyone has the right freely to participate in the cultural life of the community, to enjoy the arts and to share in scientific advancement and its benefits" [47]. Kużelewska and Tomaszuk also point out that, following the Declaration, "cultural rights have been understood as inseparable from human rights and require protection mechanisms within particular international (including regional) legal systems" [47]. In that context, they point out that Europe developed one of the most effective mechanisms of human rights protection by establishing the Council of Europe and adopting the European Court of Human Rights. However, the pandemic has almost stopped access to cultural content, so in many cases, online communication has become the only way that most of the world's population can access cultural content now under lockdown: "The recent outbreak of COVID-19 reformulated many concepts of access to human rights and possibilities to enjoy freedoms. Even if access to culture (access to cultural heritage) has been available online for many years, it is the time of globally occurring lockdowns that forced people to stay home and found themselves in a situation when all sudden online access to culture became the only way of access to culture" [47].

Measures taken to protect public health have threatened the global economy, as well as cultural activities, necessitating economic stimulus in most countries and reconfiguring the role of business in society. This applies equally to the public 'quaternary sector' and the provision of public sector services (social upgrades), which includes the cultural sector. Brammer et al. in 
their work explore an important issue: Will the role of business in society return to normal after COVID-19, or will it be reconfigured in enduring and impactful ways? In their search for an answer, they use Alexander's theory of 'societalization' to examine how socially disruptive extreme events affect the role of business in society. In this sense, the research in this article can be considered as a questioning of the new, changed, role of culture and cultural content within the context of the phenomenon of 'societalization' [48].

By July of 2020, many restrictions had already been lifted, but the concept of the '1,5-meter society' was retained, thus still prohibiting large-scale gatherings such as festivals, and severely limiting the capacity of leisure venues. The unexpected COVID-19 pandemic has forced the governments in many countries to enforce the total closure of all non-essential structures and activities, museums, and other cultural institutions included. During the lockdown period, people spent more leisure time at home and with their families. This caused a spike in the popularity of social media-related leisure, gaming, television (especially streaming services), but also a revaluing of more 'traditional' forms of leisure. Since many leisure facilities were closed, self-organized outdoor leisure activities such as hiking, running, and cycling became even more popular [49]. Some of the cultural institutions were unable to open their doors to a visiting public making the only available option the spreading of culture and knowledge through online means. This was pointed out by Agostino et al. through their statement that this avenue has caused an acceleration in digital transformation processes, but rather than through dramatic innovative technologies, it has used a channel at the fingertips of almost everyone: that of social media. They continue by pointing out the data that $45 \%$ of the world's population has a social media account [50]. The same authors state that museums are now using social media to reach a wider online public, posting virtual tours, interviews with their directors, and descriptions of artwork, as well as using the so-called gamification model - setting quizzes and running treasure hunts. In this sense, the authors re-examine the role of social media and online communication in culture and announce a change in the paradigm of marketing communication, while stating: "These initiatives have changed social media from channels of communication into tools for spreading cultural material. The current situation has led to conjectures on whether such initiatives are an effective way to increase cultural participation. It also paves the way to other considerations on the role that social media will play and, more broadly, what part will digital technology have in disseminating cultural material during 'phase two', when we are still living in proximity with the virus and going forward into the post-COVID-19 stage" [50].

Samaroudi et al. also warn of a significant increase in online communication activities during a pandemic. They elaborate that, as the impact of COVID-19 on everyday lives dawned on people early in 2020, "digital media consumption behaviour changed dramatically as millions of people converted their work, social and educational activities from land-based to digital platforms to 'shelter in place' or meet requirements for 'social distancing' that were imposed to manage the pandemic", as well as that the "UK reported a $29 \%$ increase on the time spent online and a $20 \%$ increase of people using social media" [51].

During some periods of the COVID-19 crisis, organizations of all kinds were required to restrict physical access to buildings and on-site provision of services. As expected, the galleries, libraries, archives, and museums (GLAM) sector were not exempted from the measures taken in response to the crisis. Apart from the immediate effect on institutions' workforce and finances, organizations have had to close, postpone or cancel projects, performances, exhibitions, and education programs that they offer to their audiences. One possible course of action was to adapt these offerings for online access. It was proposed that online access to these activities could reduce isolation, improve mental health and support the educational and creative needs of diverse audiences [51]. 


\section{RESEARCH METHODOLOGY}

This article presents a comparative qualitative analysis of the primary research conducted in November 2020 in the Croatian cities of Dubrovnik and Zadar. The research was conducted using an in-depth semi-structured interview with the managers of two cultural institutions the first case being one of the most famous cultural events in Croatia - the Dubrovnik Summer Festival, and the second one focused on a cultural institution - the Croatian National Theater in Zadar [52]. In both cases, the research aimed to analyse the impact of the COVID-19 pandemic on various aspects of the operations of these two institutions, with particular focus being placed on marketing communication and digital marketing. The article relies on the previous research conducted by the same authors, particularly on the research about the development of digital marketing on the example of the Croatian National Theater Zadar. Similar research projects were conducted by Agostino et al. (2020) on the example of Italian museums focused on how the Italian state museums are using social media during their many weeks of enforced closure. During the research particular attention was placed on the role of online communication, the spread of knowledge and culture through social media at a time when physical sites of culture are closed, the engagement of the public in online communications with museums during the lockdown, while also exploring the future of online user access to cultural institutions. It is interesting to notice that these authors, just like the authors of this article, rely on earlier research on cultural transformation in Italian museums by pointing out that digital innovation has taken central stage in museum reforms in 2018 with the foundation of the Italian National Museum System [50].

Similar research was conducted by Samaroudi et al. Their research was conducted during the lockdown period in the UK, from April to July 2020, when memory institutions were closed, and they started to gradually re-open their physical premises to visitors. The research aimed to understand how the cultural heritage institutions adapted during COVID-19 closures by developing their digital capabilities; how new initiatives were integrated into existing digital offerings that enabled audiences to access cultural heritage resources during physical closures; and how the distinctive needs of audiences during the COVID-19 pandemic were met by the sector [51].

Ryder also cites an example of research among 16 cultural institutions in the US to research online communication during the COVID 19 pandemic [53], while Lješnjak questions the online communication model of the Zagreb City Library during the pandemic [54].

In addition to the previous research, the authors compiled a list of questions for the semistructured interview based on their research intuition, the analysis of existing scientific theories and practices relating to the research topic, and the previous and current business experiences of the authors with strategic and operational planning, as well as subsequent practical application within the event industry and cultural activities. Furthermore, the research was conducted using a qualitative, phenomenological, and case study approach. An exploratory and descriptive analysis was used that was suitable for topics that, according to Papachroni and Lochrie, meet the following criteria: when present literature and knowledge is inadequate; research questions are often broad and the use of hypotheses is rare; they can be deliberately designed to help to build theory through inductive methods to create a hypothesis about new research questions; used when seeking to provide causal explanations explaining how events occurred; is used to present a rich and comprehensive description of an entity of interest in the context in which it transpired [55], and particularly when, as Yin states "the boundaries between phenomenon and context are not evident" [55, p.80]. According to Yin (quoted in Papachroni and Lochrie), a "case study approach is best suited to circumstances where there is limited knowledge about a phenomenon or where exiting knowledge is contradictory of unclear" [55]. 
Below is a table with lists of questions taken from the semi-structured interview conducted with the event managers, followed by a descriptive comparative analysis of the obtained answers. Within the analysis, the respondents will be marked with Roman numerals I. (Dubrovnik) and II. (Zadar), while their institutions will be marked with the letters A. (Dubrovnik Summer Festival) and B. (Croatian National Theater Zadar).

Table 1. List of questions for the semi-structured interview with event managers in Croatia.

\begin{tabular}{|c|c|}
\hline Study questions & Asked questions \\
\hline $\begin{array}{l}\text { The number of event visitors } \\
\text { during a pandemic }\end{array}$ & $\begin{array}{l}\text { Did you record a decrease in the number of visitors during } \\
\text { COVID? Can you compare the number of visitors before and } \\
\text { during COVID? (If you are able, can you give us the exact } \\
\text { number of visitors before and after the appearance of COVID?) }\end{array}$ \\
\hline $\begin{array}{l}\text { The marketing during the } \\
\text { pandemic }\end{array}$ & $\begin{array}{l}\text { Are you paying more attention to marketing now, during the } \\
\text { COVID pandemic, or has the engagement remained the same? }\end{array}$ \\
\hline $\begin{array}{l}\text { The outsourcing of } \\
\text { marketing functions during } \\
\text { the pandemic }\end{array}$ & $\begin{array}{l}\text { Do you hire marketing professionals outside of your institution? } \\
\text { In which segment of marketing do you outsource your activities } \\
\text { and which segment do you perform within the institution (before } \\
\text { and after the appearance of COVID, separately)? }\end{array}$ \\
\hline $\begin{array}{l}\text { The strategic and } \\
\text { operational impact of the } \\
\text { pandemic on the marketing } \\
\text { planning function }\end{array}$ & $\begin{array}{l}\text { Given the new situation with COVID, has there been a } \\
\text { change in business strategy, marketing strategy, and the } \\
\text { annual marketing plan? }\end{array}$ \\
\hline $\begin{array}{l}\text { The focus of marketing } \\
\text { activities and the target } \\
\text { market }\end{array}$ & $\begin{array}{l}\text { Did you keep the target market in the COVID era? What was } \\
\text { your target market before, and what is the market now } \\
\text { during the time of COVID? }\end{array}$ \\
\hline $\begin{array}{l}\text { Marketing distribution and } \\
\text { communication as } \\
\text { customized elements of the } \\
\text { marketing mix in the } \\
\text { pandemic age }\end{array}$ & $\begin{array}{l}\text { Which marketing channels have you used before, and which } \\
\text { during COVID in distribution (ticket sales)/marketing } \\
\text { (business) communication: } \\
\text { a) distribution/ticket sales? } \\
\text { b) marketing (business) communication? }\end{array}$ \\
\hline $\begin{array}{l}\text { Changes in performance } \\
\text { management and operational } \\
\text { logistics during the } \\
\text { pandemic }\end{array}$ & $\begin{array}{l}\text { What has changed in the performance: } \\
\text { a) the scope and types of program and the financial value } \\
\text { of the program before and during COVID? } \\
\text { b) logistics and the program execution? } \\
\text { c)arranging the space for the audience? }\end{array}$ \\
\hline $\begin{array}{l}\text { New models of marketing } \\
\text { communication emerged } \\
\text { during the pandemic age that } \\
\text { will persist later }\end{array}$ & $\begin{array}{l}\text { Which of the existing models of communication and/or } \\
\text { performance is so good that you will keep it (in part or in } \\
\text { full) even after the pandemic? }\end{array}$ \\
\hline $\begin{array}{l}\text { The connection between } \\
\text { event management and } \\
\text { tourism }\end{array}$ & $\begin{array}{l}\text { How do tourists fit into your target market and } \\
\text { communication (given that you operate in well-known } \\
\text { tourist destinations)? }\end{array}$ \\
\hline $\begin{array}{l}\text { The general impact of the } \\
\text { pandemic on cultural } \\
\text { institutions and their } \\
\text { business strategies }\end{array}$ & $\begin{array}{l}\text { Open question: The impact of COVID on your business? } \\
\text { List the key issues and stakeholders that can help here. How } \\
\text { will this affect your future business/marketing strategy? }\end{array}$ \\
\hline
\end{tabular}

\section{RESULTS}

The following is an overview of the results of the comparative analysis. 


\section{THE NUMBER OF EVENT VISITORS DURING THE PANDEMIC}

Institution A recorded a significant decline in the number of visitors due to the impact of the pandemic, primarily because of the epidemiological measure requiring maintaining physical distance, which reduced the capacity - the number of seats for the audience - by as much as $2 / 3$. Similarly, the number of performances was reduced. In institution $B$, the capacity was reduced first to $1 / 3$, and then to even less than $1 / 6$ of the seats, both indoors and outdoors where the programs were performed. If we compare this data with the pre-COVID period, when the audience filled up to $90 \%$ of available seats during the summer, a significant decrease in available capacity can be noticed. This was caused primarily by the introduction of the epidemiological measure to maintain physical distance between seats, which significantly reduces their available number. What also needs to be pointed out is that some epidemiological measures were also related to the determining of the maximum number of visitors per event/gathering (measures aimed at limiting gatherings), which also significantly affects business within the event industry and the cultural sector activities.

\section{THE MARKETING DURING THE PANDEMIC}

Both respondents pointed out a shift in marketing goals, with Respondent I emphasize the reduced overall budget of the festival and consequently the budget for marketing activities. Respondent, I also pointed out that significantly less money was spent on advertising in print and electronic media, as well as on the printing of promotional materials. Both respondents pointed out a stronger communication engagement with users on social networks and other online channels, while Institution A pointed out a stronger effort directed towards e-mail newsletter activities. It is interesting to note the change in practices in institution A, which is pointed out by respondent I, who states that "earlier the main goal was to increase ticket sales, while today the goal is to strengthen the brand". Institution B, on the other hand, has increased its efforts regarding content marketing and strengthening customer relationships. Ticket price reduction for all groups can also be highlighted as part of sustainable marketing and branding, which in institution A reaches up to $50 \%$, as well as the engagement on the YouTube channel in institution B, which enables their users to watch plays from the comfort of their own home - an especially important feature during lockdown and/or self-isolation of users due to epidemiological reasons. In all these activities, digital marketing has played a key role.

\section{THE OUTSOURCING OF MARKETING FUNCTIONS DURING THE PANDEMIC}

Both analysed institutions state that, as a rule, they do not outsource their marketing activities, regardless of the current pandemic, or before it. Institution A states that they have a Department for Public Relations and Marketing that conducts marketing activities, while Institution B points out that "employees in the Marketing Department within their institution regularly attend seminars and social media training to make proper use of all resources." To increase the quality of marketing content on social networks, Institution B sporadically uses outsourcing, for example in cases when the hiring of videographers outside the institution is needed for the making of trailers for the new productions and the like.

\section{THE STRATEGIC AND OPERATIONAL IMPACT OF THE PANDEMIC ON THE MARKETING PLANNING FUNCTION}

Both respondents point out that in their institutions, given the new situation with COVID, their business strategy, marketing strategy, and annual marketing plan have changed.

\section{THE FOCUS OF MARKETING ACTIVITIES AND THE TARGET MARKET}

Regarding the target market, Institution A points out that the marketing focus, due to epidemiological measures limiting travel, has shifted from the previously targeted group - 
mostly foreign tourist visitors, as they point out, "towards the local audience and the national public". Institution B, unlike Institution A, operates throughout the year, and by being a branch of the National Theater, it is, understandably, predominantly orientated towards the local audience. Before the pandemic, the most significant target groups - the subscribers consisted of the elderly population, among whom some canceled their subscription due to the global situation, then high school and university students, and finally a group of subscribers aged between 25-40, whose number increased after the beginning of the pandemic. The target group of students remained stable even after the pandemic, which is partly due to the quality cooperation of the Theater (Institution B) with the University of Zadar, and a branch of a bank that co-finances the subscription for students. Part of the program is directed towards the younger population, with an interesting event regularly taking place - an educational gettogether between students and actors named 'Coffee with actors'.

\section{MARKETING DISTRIBUTION AND COMMUNICATION AS CUSTOMIZED ELEMENTS OF THE MARKETING MIX IN THE PANDEMIC AGE}

\section{Distribution/ticket sales}

Regarding ticket sales, both institutions emphasize that they previously implemented a multichannel distribution strategy, i.e., ticket sales, with Institution A highlighting online sales, local sales, and agency sales, while in the case of Institution B the sales channels were sales at the Institution's box office, as well as online sales. In both institutions, after the outbreak of the pandemic, only the direct online sales remained stable, which, it should be noted, also contributes to the improvement of epidemiological conditions, given that it reduces congestion and queues at the box office.

\section{Marketing (business) communication}

When it comes to marketing tools, Institution A points out the wide distribution of various printed materials - posters, flyers, brochures, printed invitations that existed before the pandemic. At the beginning of the pandemic, only e-mail invitations were used, as well as a minimal number of printed materials with limited distribution, while at the same time the entire online activity increased. This is in line with the previously mentioned marketing goals, set after the occurrence of the pandemic, with the emphasis no longer on increasing the number of tickets sold, which can be classified as a classic paradigm of push or outbound marketing, but a reversal towards strengthening the brand with messages about durability, safety, professionalism, reliability, quality, trust, etc., both concerning the audience and the patrons, sponsors, and donors, which belongs to the modern paradigm of pull or inbound marketing. Institution B points out that social networks (YouTube, Instagram, and Facebook), the official website, and e-mail are all channels they used before and during the pandemic. Due to the reduced number of available tickets during the pandemic, Institution B was particularly focused on the quality of content, or, as stated by Respondent II "For users of social networks to have fun and relax". It is interesting to notice that within the same institution in their marketing communications they try to avoid placing the focus of the communication on the pandemic, and therefore COVID is not used as a keyword in the published posts.

\section{CHANGES IN PERFORMANCE MANAGEMENT AND OPERATIONAL LOGISTICS DURING THE PANDEMIC}

\section{The scope and types of program and the financial value of the program before and during COVID}

As a direct consequence of the COVID-19 pandemic on business, Respondent I pointed out: "The reduction of the budget, which resulted in planning difficulties and a significant reduction of 
program content, led to postponement or cancellation of some already agreed/contracted international collaborations, theater co-productions, and guest appearances by foreign artists." However, the Respondent continues by stating that "during the planned 47 days in 2020, the Festival presented to its loyal audience almost 50 dramas, musical, dance, folklore, and other performances on 13 different stages and locations in the city of Dubrovnik, which is approximately one third less than usual." Within Institution A the artistic focus of the program was on Croatian artists, both those who have been traditional staples, as well as faithful collaborators and co-creators of the Festival for many years, and those who found themselves as the most vulnerable group due to the pandemic, as well as young creators (freelance artists, freelancers, students, etc.) for whom the engagement at the Festival was an opportunity and an incentive for their professional activity and further development. The latter activity could certainly be included in the promoting sustainability and inclusion group, given that young people and freelancers are often neglected and marginalized population segments when it comes to engagement and inclusion in major cultural programs. Institution B emphasizes that the Drama Subscription Program remained unchanged, while the program outside of the Subscription decreased. For example, as they state, the traditional Gospel concert, which is held every year in December, could not be organized because it is not easy for foreign musicians to travel during the pandemic. During the pandemic, the emphasis is on local artists, so the program is created accordingly. The number of programs that are not organized by CNT Zadar has also decreased, and the reason for this is a reduced capacity of seats or the inability of art organizations to perform normally, which at the end of November 2020, according to epidemiological measures, were shut down completely.

\section{Logistics and the program execution}

Respondent I pointed out the difficulties relating to the traveling arrangements of artists to Dubrovnik during the pandemics. For example, she states that the traveling arrangements of the artists during the pandemic were influenced by some minor obstacles, most often due to the decreased number of available flights, while bus or boat trips were less frequent than usual, mostly due to fears of an increased likelihood of infection, as well as a decrease in available traveling options. However, the organization of the accommodation for the artists in summer 2020 was less complicated than usual due to the decline in the number of tourists, and the subsequent increase in available accommodation capacity. Measures to prevent the spread of infection within Institution A were followed in both mentioned organizational segments. It is interesting how the new epidemiological measures affect the performance of the program itself. The Respondent states that "the new situation required finding new ways to establish a relationship between the artist and the audience, so this year the approaches to the engagement, participation, and expression were somewhat different. The formats of the art programs were smaller, as was the number of audiences who had the opportunity to enjoy them, but this in no way affected the quality of the art content." Respondent II also pointed out that her institution also respects all the prescribed epidemiological measures, such as, for example, the fact that the artists on stage are distanced at least 4 meters from the audience. In the dressing room behind the stage, disinfectants have been installed and there is increased control of the entering and exiting of the audience from the theater.

\section{Arranging the space for the audience}

Within Institution A, despite unfavourable circumstances, great efforts were made to maintain safety conditions, both for its artists and its loyal audience. They indicate that for each rehearsal and performance, a record list was kept and the body temperature of the persons participating in the program was measured, as well as a spectator record containing the name, surname, contact number, and seat number. Numerous other measures were 
implemented for the program to be performed, among which Respondent I points out the following: "Audience entry required slightly more time than usual, but this was included in our organizational assessment. The Festival box offices had special protective barriers between the cashier and the visitors, and contactless payment was ensured. All seats and standing places were marked and at least 1,5 meters apart, and the recommended distance of 4 meters between the audience and the performers on stage was respected. The Festival staff had adequate protective equipment, and in organizational sectors where it was possible, teamwork was organized. Warnings about the rules of conduct were regularly displayed within the used space, while disinfectants were made available at all entrances. The use of protective masks was recommended. After each performance, all spaces (auditorium, stage, technical spaces, etc.), as well as parts of stage equipment, props, and costumes of the artist, were thoroughly disinfected."

Institution B also pointed out that they respect all epidemiological measures to make the audience feel safe. They also highlight several epidemiological adjustments in their business operations, particularly within performance management. These measures were the following: On the day of the show, the theater doors are opened 30 minutes earlier to reduce crowds. Disinfectants are placed at the entrance to the theater. During each program, the employees of CNT Zadar keep a record of the spectators, while both employees and the audience use protective masks. In the auditorium, the seats are 2 meters apart, but after the announcement of the new measures, the distance between the seats was increased to 4 meters. After each performance, the theater premises are disinfected and ventilated. Rehearsals of the latest CNT Zadar production were conducted in a particularly cautious manner, and although the premier was announced for April, due to the increased epidemiological measures, it was performed only in November. All rehearsals were conducted using protective masks.

\section{NEW MODELS OF MARKETING COMMUNICATION EMERGED DURING THE PANDEMIC AGE THAT WILL PERSIST LATER}

The respondents state that Institution A will, even after the pandemic, continue to develop and strengthen Internet marketing strategy, while Institution B will certainly continue to use digital marketing channels, especially social networks. In doing so, Respondent II also states: "We will continue to publish interesting content and communicate with our users through video calls from performers, which has proven to be a very good model of communication with the audience."

\section{THE CONNECTION BETWEEN EVENT MANAGEMENT AND TOURISM}

The importance of this connection has already been emphasized earlier, when it was stated that before the pandemic, the utilization capacity was reaching $90 \%$ in both institutions during the summer months, i.e., during the tourist season. Institution A - The Dubrovnik Summer Festival, points out that they are one of the oldest and most prestigious European festivals, hosting world-famous artists and performers for 71 years, and, as the Respondent I state, "It is not surprising that the Festival is recognized and appreciated around the world and that many visitors come to Dubrovnik to enjoy Festival performances". Because of that fact, tourists are an important part of their target market, and their marketing communication is largely geared towards them. Respondent I emphasized that the special target group of the Festival consists of British tourists while stating: "The British tourists are the largest group of visitors to Dubrovnik, they have good purchasing power and interest in cultural programs, so the Festival recognizes them as their target group and investments are made in advertising in that market, for example, ads in in-flight magazines of companies connecting British cities with Dubrovnik, advertising in Time-Out Journal, etc." Since Dubrovnik is a tourist destination 
where the largest number of visitors arrives by air, and for the Festival to achieve the maximum possible visibility for visitors, most of their marketing activities in the period before the COVID-19 pandemic were planned to follow these needs. They emphasize several things: Large advertising areas are rented in the area of international and domestic arrivals at the Dubrovnik Airport, and printed promotional materials (posters, leaflets, program brochures) in almost all hotels in the city and its surroundings, offices of tourist boards and tourist agencies, in part of the private accommodations as well as a part of taxi carriers; the posters of the Festival that are displayed in public city areas: publicities (20 locations), owned stands (more than 50), city-lights locations at bus stations, and digital totems; promotion of the Festival in the public city areas in the old town - publicity posters, owned stands, banners $\left(3 \times 4 \mathrm{~m}^{2}\right)$ and daily video projections functioning as a promotional channel. It can be concluded that these forms of promotion during the pandemic have been almost completely replaced by digital marketing, as well as, as noted earlier, by focusing on the local population and domestic tourists. Finally, it should be added that Dubrovnik is one of the strongest tourist brands in the Mediterranean, and therefore the Festival, as a renowned cultural event with a long tradition, will certainly return in its full glory in the post-pandemic era. Institution B also stresses the long tradition of their main summer program - the Zadar Summer Theater Festival that has been running since 1995. It is a rich and informative program that takes place in open locations in the city of Zadar and nurtures primarily comedy as a genre. It is held from June to August. "During its 26 years of existence", as stated by Respondent II, "a total of 19 local productions were performed, with over 200 guest titles from all over Croatia and the world." Since 2005, the event has been enriched with a music program - a three-day festival titled Zadar Jazz \& Blues Festival, which, during the past five years, has brought together world-renowned musicians. Zadar is also a coastal tourist destination, so tourists, in a way, fit into the target market of the CNT Zadar. Here it is also important to stress the quality of cooperation with the Zadar Tourist Board which conducts online promotional activities for the Theater.

\section{THE GENERAL IMPACT OF THE PANDEMIC ON CULTURAL INSTITUTIONS AND THEIR BUSINESS STRATEGIES}

Respondent I point out that the key problems caused by the pandemic in Institution A - the Dubrovnik Summer Festival are the following: "The uncertain revenues and reduced budgets, a significant reduction in audience numbers and health risks for the audience and employees". Until the end of the pandemic, which, it is assumed, should eliminate the mentioned problems, the most helpful thing is a transparent, open, direct, and honest communication among stakeholders" concludes Respondent I. Respondent II for his/her institution states that the COVID pandemic primarily stimulated creativity in the CNT Zadar, making the Theatre open to the audience in a completely different way. An increase in the engagement and activities on social networks was noticed in that institution, as well as the establishment of new models of communication with foreign artists and teams of authors that sent their video materials that were used as announcements within the communication content on social networks. The organization went beyond the traditional approaches and in such a way brought theater into the home of its audience. In March 2020, during the lockdown period, free online performances produced by CNT Zadar were presented over the CNT Zadar YouTube channel, thus enabling the loyal audience to watch a theatrical play from the comfort of their own home. The fact is that financial resources have decreased during the pandemic, therefore challenging cultural institutions. However, Respondent II states that "CNT Zadar is ready for any situation and all for the benefit of its audience".

\section{DISCUSSION}

It seems that the COVID-19 pandemic has blurred the usually sharp dividing line between cultural institutions and their users, although this line seemed to be sharpened at the start of 
the pandemic, due to strict epidemiological measures. A significant role was played here by online communication, which kept the relationship between culture and its users alive in almost impossible, and sometimes even completely impossible, conditions for performing events and cultural programs. This is shown by the results of the research conducted in this article, and a similar conclusion reached by Rowen who emphasizes the importance of "creative and pro-social responses of members of one such transformational festival culture" which he calls "subversive inter-subjective inversions" which have as a consequence "the recognition, in-itself, and production, for-itself, of a shared humanity of co-creators and participants in not just ephemeral, but accretive transformational social and environmental projects" [56]. We witness this creative transformation in the field of marketing communication, but also the performance of theater programs on the example of Croatian cultural institutions analysed in this article, with special attempts being made in emphasizing the brand of the cultural institutions in new ways and designing new creative content for users of different online channels. It is especially interesting to point out that the conditions of the pandemic and the reduced number of audience poses a challenge for the artists themselves during the performance, who devise new, creative ways of approaching and communicating with the audience during the program, which is especially noticeable in the Croatian National Theater Zadar. The pandemic did not, therefore, disrupt the sensitive relations between the analysed cultural institutions and the audience. On the contrary, new ways of communication led to an increased interest of part of the audience to consume cultural content, while, for more vulnerable groups, online transmissions of cultural content were devised for them to be able to consume the content from the comfort of their homes (example CNT Zadar). A shift from classic marketing and brand strategies to more modern ones has been noticed, which represents new ways of building competitiveness, even where that competitiveness is less pronounced, as is the case with cultural institutions. This confirms the previously mentioned thesis proposed by Lindström about the importance of a comprehensive and systematic understanding of the impact of the COVID-19 pandemic on possible coping strategies [5].

The justification of the research goal set in this article, which is to investigate primarily the impact of the pandemic on digital marketing, is consistent with the theses presented by Yudiyana et al. [21], who advocate further research of digitization within the event industry. Accordingly, the digitalization of marketing communication is considered one of the key determinants of the sustainability of the event industry and cultural institutions - moreover it is precisely the digital channels that managed to keep alive the two observed institutions during the pandemic, although on a significantly reduced scale, reduced budgets, and a reduced capacity and number of presented programs. It is these key consequences of a pandemic on the event industry that the previously mentioned author Szatan [29] warns about by pointing out other accompanying risks in the event industry during a pandemic. Szatan is followed by Surplice [28] who emphasizes that "social distancing measures are impossible to control at any festival". The research presented in this article refutes this thesis through the example of the Dubrovnik Summer Festival, which managed, in a very successful and controlled manner during 2020, to maintain its cultural program in a somewhat reduced volume. This was used by the Festival as a type of advantage, at least when it comes to the previously marginalized audience, namely the local population and domestic tourists, to whom the activities were now devoted to a greater extent. The research in this article presents in detail the epidemiological measures taken in cultural institutions during the COVID-19 pandemic, as some authors believe that "events are considered as one of the biggest sources for the transmission of infectious diseases" [25]. A certain "toughness" and flexibility in business should be observed in both analysed institutions. Namely, they have survived the pandemic, at least for now, despite the generally accepted thesis that there are no events and cultural programs during the pandemic, given that most events were cancelled and postponed 
by the organizers as per the guidelines announced by the government. It is interesting to notice that the Croatian National Theater also operated during the lockdown, following the so-called hybrid model proposed by the previously cited Schulz (cited in [29]), in a way that the cultural programs were presented using the YouTube channel [29]. Similarly, Ryder finds solutions and answers to the crisis through digital content enrichment and states that digital content builds communities through live and serialized content, partnerships, fundraising, increased transparency, and increased accessibility during temporary closures, categories that are mentioned by both respondents in the interview. The same author emphasizes the importance of increased social media engagement, as well as content campaigns such as videos, blogs, partnerships, and paid educational content, which was also confirmed in the research because social media marketing was highlighted as being very significant for both analysed institutions [53]. If we look at the authors who explore new trends and innovations in digital marketing in culture, which they wrote about before the COVID-19 pandemic, we can see that all these trends accelerated during the pandemic, which is confirmed by the research presented in this article. It can be stated that the pandemic in this sense has acted as a catalyst for change towards better communication and the strengthening of the relationship with customers $[30,41]$.

These theses can also serve as practical implications for implementation in cultural institutions and their marketing and management system, where the adaptation and digitalization, as well as brand strengthening and a more significantly "sophisticated" use of online marketing tools, especially social networks, as channels used for more informal and personal communication with users, are of crucial importance. This has been proved by international experiences, but also by the research presented in this article. Likewise, both the research in this article and similar international research, for example, Samaroudi et al. [51], show that, under the influence of the pandemic, cultural institutions will increasingly focus on content marketing, integrated marketing channels, and the delivery of values, programs and cultural content that are relevant and in line with the cultural needs of the community. This will also allow faster and easier access to culture, which, according to some, at least in some segments before the pandemic, was somewhat ghettoized and "reserved for elites", and was particularly not interesting to many members of the younger generation. It can therefore be argued that the digital transformation within cultural institutions has already begun, i.e. it began to develop in a significant manner precisely at the time of the pandemic and because of the pandemic. It is particularly recommended therefore to focus on new or until now marginalized market segments, as well as the strengthening of the Customer Relationship Management (CRM) segment, and the reaffirmation of the brand of the institution and its programs.

The new issues concerning the post-lockdown period are not only those focused on devising optimal operational and user communicational models of cultural institutions. According to the authors of this article, the COVID-19 pandemic has opened some other issues concerning the role and place of culture and cultural content for different social groups, the audience engagement regarding content selection, and the co-creation of cultural programs, the interpretation and audience participation in the programs, as well as several other issues related to the greater permeation of culture and social everyday life, which in some segments of culture before the pandemic seemed more distant than ever. Weed asks the same question when it comes to sports and tourism by stating: "A challenge is set for managers, administrators and researchers working at the interface of sport and tourism to look outwards beyond their development concerns and recognize and accept both a responsibility and an opportunity to make these contributions" [57]. Thus, a crisis creates new opportunities, but also brings new responsibilities. Of course, it must be emphasized that we must not forget the "real" physical space, which will never be able to be completely replaced by an online reality. 
Or, as Lješnjak states, that "the best business model is, as always, somewhere in the middle, between the digital and the traditional" [54, p.52].

The scientific contribution of this article is to explore what types of digital content cultural institutions implemented during COVID-19 and their effects on marketing engagement. Existing research identified the role of digital content and social media in cultural institutions, but only in times of normal operations. The study in this article adds to the existing literature by exploring types of digital content implemented, impacts on social media engagement, impacts on other aspects of business, and future implications regarding the COVID-19 pandemic. From the comparison of research results in this article and similar international research, it can be concluded that the response to the pandemic in cultural institutions around the world is probably similar and that many of them are ready to face such a global crisis unprecedented in modern history, based on the principles of flexibility and digitalization of business, brand repositioning, and stronger customer orientation. This hypothesis should be extended through further research and international comparative analysis. This would allow for an in-depth analysis of the adjustment of business and risk management systems in cultural institutions and the event industry.

The mentioned changes that were triggered by the appearance of the pandemic are not ephemeral, but essential, and they enter the very core of the concept of cultural and entertainment gatherings, as well as culture itself and cultural events, today and in the future. In the article titled "Theater in The Apocalypse", Liyanage questions the role of the theater during and after a pandemic by stating: "We think that this proscenium theater is going to be ceased because of the corona outbreak. But theater in its broader sense is not limited to theater as an architectural structure. With this new world order, the theater will be flourished with novel modes of practice and reception" [58]. Katara explains: "Theater has survived through many ages and millennia. Theater thrived during the great depression and the world wars. Theater found more meaning in the conflicts that humanity has faced and emerged with new forms, new content, and new pedagogies. As the world faces the pandemic, with almost every country in the world is either in Lockdown mode or slowly finding its way out the major question is not how theatre will survive the crisis, for it has and it will, irrespective of what the circumstances are, but the question is what will this crisis yield at the end?" [59].

In this sense, further queries should be made, and scientific and professional answers should be researched regarding the question: Quo Vadis, culture? Where is, and what is in general, today, and what will it be tomorrow, a theatre, or some other theatrical, musical, entertaining, or similar event? In his book, The Empty Space Peter Brook tries to answer this question by stating: "I can take any space and call it a bare stage. A man walks across this space whilst someone else is watching him, and this is all that is needed for an act of theatre to be engaged." [60, p.11]. Perhaps this very claim can be an excellent basis for further pursuits of answers in this field.

\section{CONCLUSION}

Under the influence of the pandemic, festivals and other cultural events are transforming, and the COVID-19 pandemic has served as a "catalyst for change" for the future. Changes in the space-time sphere when it comes to theatres, festivals, and other events bring a new role and function of cultural institutions and emphasize the importance of culture in the lives of individuals. This is best seen in the conditions of a pandemic in which cultural contents cannot or can only partially be consumed. The lessons learned from the pandemic, therefore, apply equally to cultural institutions as to the public. In both institutions investigated in this article, a quick and creatively designed response to the pandemic situation was found, and 
therefore their activities continued despite the difficulties, in an adapted and somewhat "reduced" manner. It should be emphasized that both institutions have relatively good levels of expertise and capacity in terms of digital technologies.

These theses corroborated the claims of the authors who also emphasize the enormous consequences of the pandemic on society [1], as well as those who emphasize the emergence of a "new normal" for citizens and business organizations. The authors emphasize the rapid adaptation of business to the new conditions [5], which was explored in this article, on the example of cultural institutions. Madray [6] points out the losses in the event industry at the global level, which is partially highlighted in the research presented in this article (reduced capacity, number of programs, budget). Although domestic authors to a somewhat lesser extent analyse the issue of the impact of the pandemic on cultural institutions, Mikac [14] nevertheless points out that the Republic of Croatia has responded well to the pandemic crisis. In a narrower sense, the research in this article focuses on the application of digitalization in business, especially in marketing communication, which Yudiyana [21] considers a significant factor in business, while partly being focused on crisis management (for example in the segment where adjustments in performance management within cultural institutions are investigated) relating to the thesis proposed by Surplice [28] and some other authors, as well as some earlier authors who researched the field of risk management [24]. The sensitivity of the event industry and cultural activities, which is as well the area of research in this article, is also discussed by Mohanty et al. [25] by highlighting the particular sensitivity of tourism and global events to the crisis. In this article, the authors also look for answers as to whether the COVID-19 pandemic has built new models in the event industry and cultural activities that will survive in the future, similar to the research conducted by Davies [26] and Salti [27]. Methodologically, the primary research of experts, with the help of in-depth interviews, relies on similar research [6], while the application of the case-study method used in this article is recommended for business and management, particularly when it relates to the meaning of context for the observed phenomenon, which is a very important feature of the researched issue, as well as when it comes to a new and insufficiently researched phenomenon [55], as is the case of the impact and consequences of the COVID-19 pandemic on business.

It has been shown that flexibility in business and dynamization and the "strengthening" of multichannel online communication with the use of several different creative models has played a key role in the "pandemic survival" of cultural institutions. It is therefore recommended to further embed digital marketing within marketing strategies, as well as to strengthen the brand itself and CRM.

The assumption is that even in this post-pandemic era, many of these models will continue to be used by the cultural institutions and that they, similarly to for-profit companies, will become digital-first and costumer-oriented organizations. It seems that these are also the basic trends towards the future, which the pandemic has only accelerated and intensified. This research focuses on the analysis of two Croatian cultural institutions - one is a theater, and the other is one of the most renowned cultural festivals in the region. This is also the basic limitation of this article, so it is recommended for further research to focus on other groups of organizations in culture, but also in sports, entertainment, and other areas of social activities that are more endangered by the pandemic. At the same time, the research can be extended to an international level, so that a comparative analysis of different international experiences can be conducted. This article also contains useful tips for the implementation of certain marketing strategies and tactics, especially digital tools, in the business of cultural institutions and beyond. In a broader sense, the message of this article is to ask in which direction society, business organizations, culture, entertainment, and other social activities will develop, together with attitudes, tastes, and above all, the behaviour of individuals - "consumers" 
of such social programs and "products". This is certainly a very complex question that can be answered only through a networked and multidisciplinary collaboration of scientists and experts of different profiles and scientific fields. But certainly, as in any other crisis, this crisis should be accepted as an opportunity, and it should encourage thinking and efforts to make the "new normal" both "better normal", and a path to building a better society, new values, and better relations between people.

\section{REFERENCES}

[1] Ratten, V.: Coronavirus (covid-19) and entrepreneurship: changing life and work landscape.

Journal of Small Business \& Entrepreneurship 32(5), 503-516, 2020, http://dx.doi.org/10.1080/08276331.2020.1790167,

[2] World Health Organization: Rolling updates on coronavirus disease (COVID-19). https://www.who.int/emergencies/diseases/novel-coronavirus-2019/events-as-theyhappen, accessed $29^{\text {th }}$ January 2021,

[3] World Health Organization: WHO Director-General's opening remarks at the media briefing on COVID19 - 11 March 2020.

https://www.who.int/dg/speeches/detail/who-director-general-s-opening-remarks-atthe-mediabriefing-on-covid-19---11-march-2020, accessed $29^{\text {th }}$ January 2021,

[4] Rappeport, A. and Smialek, J.: I.M.F. Predicts Worst Downturn Since the Great Depression.

https://www.nytimes.com/2020/04/14/us/politics/coronavirus-economy-recession-depression.html, accessed: $29^{\text {th }}$ January 2021 ,

[5] Lindström, M.: The COVID-19 pandemic and the Swedish strategy: Epidemiology and postmodernism.

SSM-population Health 11, 100643, 2020, http://dx.doi.org/10.1016/j.ssmph.2020.100643,

[6] Madray, J.S.: The Impact of COVID-19 on Event Management Industry.

International Journal of Engineering Applied Sciences and Technology 5(3), 533-535, 2020, http://dx.doi.org/10.33564/IJEAST.2020.v05i03.089,

[7] Madhav, N., et al.: Pandemics: risks, impacts, and mitigation.

In: Madhav, N., et al.: Disease Control Priorities.

Improving Health and Reducing Poverty 9, 2017,

http://dx.doi.org/10.1596/978-1-4648-0527-1_ch17,

[8] Qiu, W.; Rutherford, S.; Mao, A. and Chu, C.: The pandemic and its impacts.

Health, culture and society $\mathbf{9}(1-11), 2017$,

http://dx.doi.org/10.5195/HCS.2017.221,

[9] Correia, S.; Luck, S. and Verner, E.: Pandemics Depress the Economy, Public Health Interventions Do Not: Evidence from the $1918 \mathrm{Flu}$.

SSRN, 2020,

http://dx.doi.org/10.2139/ssrn.3561560,

[10]James, S. and Sargent, T.C.: The economic impact of an influenza pandemic.

Canada Department of Finance, Working Paper 2007-04, 2006,

https://epe.lac-bac.gc.ca/100/200/301/finance/working_papers-ef/2007/wp2007-04e.pdf, accessed $30^{\text {th }}$ April 2021,

[11]Meltzer, M.I.; Cox, N.J. and Fukuda, K.: The economic impact of pandemic influenza in the United States: priorities for intervention.

Emerging infectious diseases 5(5), 659-671, 1999, http://dx.doi.org/10.3201/eid0505.990507,

[12]Bloom, E.; De Wit, V. and Carangal-San Jose, M.J.: Potential Economic Impact of an Avian Flu Pandemic on Asia.

http://hdl.handle.net/11540/2165, accessed $30^{\text {th }}$ April 2021, 
[13] Smith, R.D.; Keogh-Brown, M.R.; Barnett, T., and Tait, J.: The economy-wide impact of pandemic influenza on the UK: a computable general equilibrium modelling experiment. BMJ 339(7733), b4571, 2009, http://dx.doi.org/10.1136/bmj.b4571,

[14] Mikac, R.: COVID-19 Pandemic and Crisis Management in the Republic of Croatia. Anali Hrvatskog politološkog društva 17(1), 31-55, 2020, http://dx.doi.org/10.20901/an.17.02,

[15]Benjamin, S.; Dillette, A. and Alderman, D.H.: “We can't return to normal”: committing to tourism equity in the post-pandemic age.

Tourism Geographies 22(3), 476-483, 2020, http://dx.doi.org/10.1080/14616688.2020.1759130,

[16] Fonseca, C.; Jorge, C.; Reis, D. and do Carmo, M.: Pandemic tourism: the new era of catering sector after Covid-19.

Anatolia 32(1), 161-164, 2020, http://dx.doi.org/10.1080/13032917.2020.1851092,

[17]Zenker, S. and Kock, F.: The coronavirus pandemic - A critical discussion of a tourism research agenda.

Tourism management 81, 104164, 2020, http://dx.doi.org/10.1016/j.tourman.2020.104164,

[18]Evans, A.B., et al.: Sport in the face of the COVID-19 pandemic: towards an agenda for research in the sociology of sport.

European Journal for Sport and Society 17(2), 85-95, 2020,

http://dx.doi.org/10.1080/16138171.2020.1765100,

[19]Pedersen, P.M.; Ruihley, B.J. and Li, B.: Perspectives on Covid-19's Impact on the Sport Industry.

Routledge, London, 2021,

[20]Miles, L. and Shipway, R.: Exploring the COVID-19 pandemic as a catalyst for stimulating future research agendas for managing crises and disasters at international sport events.

Event Management 24(4), 537-552, 2020, http://dx.doi.org/10.3727/152599519X15506259856688,

[21] Yudiyana, I.M.G.; Sumichan, A. and Ariyani, N.W.S.: Management Information System of Event Organizer.

International Journal of Engineering and Emerging Technology 3(2), 116-122, 2019,

[22]Lee, S.S.; Goldblatt, J.J. and Daniels, M.J.: A Comparative Analysis of the Perceived Effects of Two Economic Recessions on Event Organizations.

Tourism Review International 16(1), 59-67, 2012, http://dx.doi.org/10.3727/154427212X13431568321582,

[23]Reid, S. and Ritchie, B.: Risk management: Event managers' attitudes, beliefs, and perceived constraints.

Event management 15(4), 329-341, 2011, http://dx.doi.org/10.3727/152599511X13175676722528,

[24] Tarlow, P.E.: Event risk management and safety. John Wiley \& Sons, Inc., New York, 2002,

[25] Mohanty, P.; Himanshi, D. and Choudhury, R.: Events Tourism in the Eye of the COVID-19 Storm: Impacts and Implications.

In: Arora, S. and Sharma A., eds.: Event Tourism in Asian Countries: Challenges and Prospects. Apple Academic Press, 2020, http://dx.doi.org/10.2139/ssrn.3682648,

[26] Davies, K.: Festivals Post Covid-19.

Leisure Sciences 43(1-2), 184-189, 2020,

http://dx.doi.org/10.1080/01490400.2020.1774000, 
[27] Salti, R.: Do Not Go Gentle into That Good Night: Film Festivals, Pandemic, Aftermath. Film Quarterly 74(1), 88-96, 2020,

http://dx.doi.org/10.1525/fq.2020.74.1.88,

[28] Surplice, P.: Fear for Festivals. http://www.open-access.bcu.ac.uk/10852/1/Fear\%20for\%20Festivals.pdf, accessed $30^{\text {th }}$ April 2021,

[29] Szatan, G.: Should I stay or should I go: how coronavirus is jeopardising music festivals. https://www.theguardian.com/music/2020/apr/15/abort-retry-fail-how-coronavirus-is-jeopardisingmusic-festivals, accessed $30^{\text {th }}$ April 2021,

[30]Mahony, S.; Spiliopoulou, A.; Routsis, V. and Kamposiori, C.: Cultural institutions in the digital age: British museum's use of Facebook insights.

Participations: Journal of Audience \& Reception Studies 11(1), 286-303, 2017,

[31]Hill, E.; O'Sullivan, C. and O'Sullivan, T.: Creative Arts Marketing, second edition. Routledge, Oxon \& New York, 2018,

[32] Shahhosseini, A. and Ardahaey, F.T.: Marketing mix practices in the cultural industry. International Journal of Business and Management 6(8), 230-234, 2011, http://dx.doi.org/10.5539/ijbm.v6n8p230,

[33] Colbert, F. and St James, Y.: Research in arts marketing: evolution and future directions. Psychology \& Marketing 31(8), 566-575, 2014, http://dx.doi.org/10.1002/mar.20718,

[34]Camarero, C.; Garrido, M.J.; Vicente, E. and Redondo, M.: Relationship marketing in museums: influence of managers and mode of governance.

Public Management Review 21(10), 1369-1396, 2019, http://dx.doi.org/10.1080/14719037.2018.1550106,

[35]Weber-Kainz, B.: Strategies for tourism internationalization of museums: topic 'Museums and cultural tourism'. In Croatian. Informatica museologica 36(3-4), 30-34, 2005, http://dx.doi.org/10.1016/S0197-2510(05)70120-0,

[36] Hume, M.: How do we keep them coming?: examining museum experiences using a services marketing paradigm.

Journal of Nonprofit \& Public Sector Marketing 23(1), 71-94, 2011, http://dx.doi.org/10.1080/10495142.2011.548759,

[37]Lehman, K.: Australian museums and the modern public: a marketing context. The Journal of Arts Management, Law, and Society 39(2), 87-100, 2009, http://dx.doi.org/10.3200/JAML.39.2.87-100,

[38]Tomičić Furjan, M.; Tomičić-Pupek, K. and Pihir, I.: Understanding Digital Transformation Initiatives: Case Studies Analysis.

Business Systems Research 11(1), 125-141, 2020, http://dx.doi.org/10.2478/bsrj-2020-0009,

[39]Krajnović, A.; Gospić, P. and Sikirić, D.: Strategic impact of digital marketing and CRM tools in tourism. In Croatian.

In: Dobrinić, D., ed.: Book of Papers of $2^{\text {nd }}$ Croatian Direct Marketing Association Conference, Varaždin, pp.209-221, 2017,

[40]Duka, I.: New trends and tools in digital marketing. M.Sc. Thesis. University of Zadar, Zadar, 2017,

[41]Ćurlin, T.; Jaković, B. and Miloloža, I.: Twitter usage in tourism: literature review. Business Systems Research 10(1), 102-119, 2019, http://dx.doi.org/10.2478/bsrj-2019-0008,

[42] Constantinides, E. and Fountain, S.J.: Web 2.0: conceptual foundations and marketing issues.

Journal of Direct, Data and Digital Marketing Practice 9(3), 231-244, 2008, http://dx.doi.org/10.1057/palgrave.dddmp.4350098, 
[43]Ryan, D. and Jones, C.: Understanding Digital Marketing: Marketing Strategies for Engaging the Digital Generation.

Kogan Page Ltd., London \& Philadelphia, 2009,

[44]Rancati, E. and Gordini, N.: Content marketing metrics: theoretical aspects and empirical evidence.

European Scientific Journal 10(34), 92-104, 2014,

http://dx.doi.org/10.1021/cen-09210-ad17,

[45]Ritzer, G. and Jurgenson, N: Production, consumption, prosumption: the nature of capitalism in the age of the digital 'prosumer'.

Journal of Consumer Culture 10(1), 13-36, 2010,

http://dx.doi.org/10.1177\%2F1469540509354673,

[46]Baranowski, P.; Korczak, K. and Zając, J.: Forecasting Cinema Attendance at the Movie Show Level: Evidence from Poland.

Business Systems Research 11(1), 73-88, 2020, http://dx.doi.org/10.2478/bsrj-2020-0006,

[47]Kużelewska, E. and Tomaszuk, M.: European Human Rights Dimension of the Online Access to Cultural Heritage in Times of the COVID-19 Outbreak.

International Journal for the Semiotics of Law-Revue internationale de Sémiotique juridique, $1-13,2020$,

[48]Brammer, S.; Branicki, L. and Linnenluecke, M.K.: COVID-19, Societalization and the Future of Business in Society.

Academy of Management Perspectives 34(4), 493-507, 2020,

http://dx.doi.org/10.5465/amp.2019.0053,

[49]van Leeuwen, M.; Klerks, Y.; Bargeman, B.; Heslinga, J. and Bastiaansen, M.: Leisure will not be locked down-insights on leisure and COVID-19 from the Netherlands.

World Leisure Journal 62(4), 339-343, 2020, http://dx.doi.org/10.1080/16078055.2020.1825255,

[50]Agostino, D.; Arnaboldi, M., and Lampis, A: Italian state museums during the COVID19 crisis: from onsite closure to online openness.

Museum Management and Curatorship 35(4), 362-372, 2020,

http://dx.doi.org/10.1080/09647775.2020.1790029,

[51] Samaroudi, M.; Echavarria, K.R. and Perry, L.: Heritage in lockdown: digital provision of memory institutions in the UK and US of America during the COVID-19 pandemic.

Museum Management and Curatorship 35(4), 337-361, 2020, http://dx.doi.org/10.1080/09647775.2020.1810483,

[52]Krajnović, A.; Perković, A. and Rajko, M: Digital Marketing in Cultural Institutions Example of Cultural Institutions of the City of Zadar.

In: Proceedings of the ENTRENOVA - ENTerprise REsearch InNOVAtion Conference, 10-12 September 2020, Zagreb (Virtual Conference). IRENET - Society for Advancing Innovation and Research in Economy, 6(1), 341-352, 2020,

[53] Ryder, B.N.: Cultural Institutions Digital Responses To COVID-19 Temporary Closures. Honors Undergraduate Theses. 820, 2020,

[54]Lješnjak, I.: Crisis communication of the Zagreb City Library with its users during the COVID-19 pandemic. M.Sc. Thesis. In Croatian.

University of Zagreb, Faculty of Humanities and Social Sciences, Department of information and Communication sciences, Zagreb, 2020,

[55]Papachroni, A. and Lochrie, S. Case Studies and data.

In: O'Gorman, K. and MacIntosh, R., eds: Research Methods for Business and Management. Goodfellow Publishers, Oxford, pp.75-95, 2015, http://dx.doi.org/10.23912/978-1-910158-51-7-2778, 
[56]Rowen, I.: The transformational festival as a subversive toolbox for a transformed tourism: lessons from Burning Man for a COVID-19 world.

Tourism Geographies 22(3), 695-702, 2020,

http://dx.doi.org/10.1080/14616688.2020.1759132,

[57]Weed, M.: The role of the interface of sport and tourism in the response to the COVID19 pandemic.

Journal of Sport \& Tourism 24(2), 79-92, 2020,

http://dx.doi.org/10.1080/14775085.2020.1794351,

[58]Liyanage, S.: Theater In The Apocalypse.

https://www.colombotelegraph.com/index.php/theater-in-the-apocalypse, accessed $29^{\text {th }}$ January 2021 ,

[59] Katara, N.: The Theater and The Crisis.

Sambhāṣaṇ 1(04), 96-101, 2020,

http://dx.doi.org/10.1111/tan.13822,

[60]Brook, P.: The Empty Space: A Book About the Theater: Deadly, Holy, Rough, Immediate.

https://cdn.preterhuman.net/texts/religion.occult.new age/occult.conspiracy.and.related/Brook, \% 20Peter\%20-\%20The\%20Empty\%20Space.pdf, accessed 21st January 2021. 